\title{
PREDICTIVE DEVICES AND THE INDIVIDUALIZATION OF JUSTICE
}

\author{
Sheldon GluecK*
}

I

It is becoming belatedly evident to scholars and practitioners in the administration of criminal justice that the most pervasive and complex issue is not so much the definition of crimes and the manner of their proof, but rather how to obtain a more efficient and just system of sentencing. The familiar cliché about the need to "individualize justice" had worn thin before it was quite clear exactly what individualization involves.

How can a court individualize the sentence? This fundamental question has been all too lightly treated in the literature, the statutes, and penologic congresses. It has just been assumed that, given a probation officer's investigation report on the particular offender before him for sentence, the judge will, by his learning and experience, be able to decide the exact penal or correctional measure suited to the particular person undergoing sentence, as well as the limits of the time the offender needs to be subjected to such treatment in order to reform or be rendered nondangerous.

But truly to "individualize" the sentence in the case of any specific offender means, first, to differentiate him from other offenders in personality, character, sociocultural background, the motivations of his crime, and his particular potentialities for reform or recidivism; and, secondly, to determine which, among a range of punitive, corrective psychiatric and social measures, is best adapted to solve the special set of problems presented by that offender in such a way as materially to reduce the probability of his committing crimes in the future. When one pauses to reflect on all that this implies, it becomes evident that to speak glibly about "individualization" is one thing; to be able to accomplish it is quite another.

- A.B. 1920, George Washington University; LL.B., LL.M. 1920, National University; A.M. I922, Ph.D 1924, D.Sc. 1958, Harvard University; LL.D. 1948, University of Thessalonika. Roscoe Pound Professor of Law, Harvard University; Member, Advisory Committee, American Law Institute's Youth Correction Authority Model Bill and Penal Code; Member, United States Supreme Court Advisory Committee on Rules of Criminal Procedure. Adviser to Justice Robert $\mathrm{H}$. Jackson on the law governing the war crimes trials at Nuremburg. Author, Mental Disorder and the Criminal Law (1925), Crime and Justice (1936), War Criminals: Their Prosecution and Puntshment (i944), The Nuremberg Trial and Aggressive War (1946), Crimse and Correction (1952); co-author [with Eleanor T. Glueck], 500 Criminal Careers (1930), One Thousand Juventle Delinguents (1934), Five Huddred Delinguent Women (1934), later Criminal Careers (1937), Juvenile Delinguents Grown Up (i940), Criminal Careers in Retrospect (1943), After-Conduct of Discharged Offenders (I945), UnRaVeling Juvenile Dezinguency (1950), Deitnouents in the Making (1952), Phystoue and Delinquency (x956); co-author [with Livingston Hail], Criminal Iaw Sylzabus (I938), Cases on Criminal Law (I940), Criminal Law \& Enforcement (1951). Editor, Probation and Criminal Justice (1933), The Welfare State and Nationat Welfare (1952); co-editor [with Eleanor T. Glueck], Preventing Crime (1936). Contributor to legal, psychological, and sociological journals. 
It is time, therefore, that reformers of the criminal law faced the fact that the feasibility of a reliable technique of individualization is crucial to the entire program of scientific and humane criminal justice. If, in fact, a reasonably sound individualization cannot be accomplished by the means at hand, then, despite the lofty aims of modern correctional philosophy, and regardless of the most elaborate investigations and case histories, the system will not work.

\section{II}

It is no wonder that, considering that individualization is a very difficult art, the product of judicial discretion in the sentencing process has not been good. It reflects a certain guesswork and even arbitrariness. Outstanding administrators have been disturbed by the haphazard product of criminal justice as seen in the sentencing results. Thus, in his 1940 Annual Report, Attorney General Robert H. Jackson complained: 1

Inequality and disparity between sentences imposed in different districts for similar offenses involving like circumstances is a troublesome and vexatious problem.... It is obviously repugnant to one's sense of justice that the judgment meted out to an offender should be dependent in large part on a purely fortuitous circumstance; namely, the personality of the particular judge before whom the case happens to come for disposition. While absolute equality is neither desirable nor attainable, a greater approach to similarity of treatment than now prevails appears to be desirable, if not essential.

Although sentencing practices in the federal courts have improved in recent years, there are still evidences of erraticism. Thus, in the 1955 report of the Federal Bureau of Prisons, the average sentence for all offenses to federal institutions during the fiscal year ended June 30, I955, was twenty-five months. While in the Third Circuit as a whole the mean was 24.4 months, looking at the picture by districts, the average sentence in Delaware was 13.7 months; in New Jersey, 20.8 months; in the Eastern District of Pennsylvania, 21.6 months; in the Middle District of Pennsylvania, fifty-three months; and in the Western District of Pennsylvania, 25.7 months. The sentences for individual crimes also varied with the different districts. There were similar divergencies in other circuits. ${ }^{2}$

In the important choice between imprisonment and probation, there was also considerable disparity. True, in the Third Circuit, the proportion of persons placed on probation in the different districts was remarkably uniform, ranging from fortyeight per cent in the Western District of Pennsylvania to 54.6 per cent in the Middle District of Pennsylvania; but such consistency did not exist in a number of the other circuits. For example, in the First Circuit, the total percentage of probation was 6r.8 per cent, or almost twice that of the 34.5 per cent norm throughout the federal system; in Maine, it was 39.6 per cent, while in New Hampshire, it rose to 84.2 per cent. So, also, in the Second Circuit, the total proportion of probationers

${ }^{1}$ Att'y Gen. Ann. Rep. 5-6 (1940). See also, id. at 11-12, 36 (1941); id. at I7 (1942).

${ }^{2}$ U.S. Buresu of Prisons, Dep't of Justice, Federat Prisons, 1955, table 22, at 74-77 (1956). At the time the above was written, neither the 1956 nor the 1957 reports was available. 
was forty-one per cent; but in Connecticut, it was 53.3 per cent, while in the Northern District of New York, it was only 29.I per cent, and in the Eastern District of New York, it was thirty-seven per cent. Similarly, the percentages of probationers received from the courts by the federal probation system ranged in the Fourth Circuit from 25.5 per cent in Maryland to sixty-two per cent in the Eastern District of North Carolina; in the Fifth Circuit from 8.4 per cent in the Western District of Texas to sixty-seven per cent in the Southern District of Mississippi; in the Sixth Circuit from 8.5 per cent in the Western District of Tennessee to 39.5 per cent in the Eastern District of Michigan; in the Seventh Circuit from I9.9 per cent in the Southern District of Indiana to forty-six per cent in the Eastern District of Wisconsin; in the Eighth Circuit from 28.I per cent in the Eastern District of Missouri to 52.3 per cent in the Eastern District of Arkansas; in the Ninth Circuit from 5.5 per cent in Arizona to $5^{1.2}$ per cent in Oregon; and in the Tenth Circuit, omitting territories, from 29.9 per cent in Wyoming to 67.9 per cent in Utah. ${ }^{3}$

To be sure, the indicated differences in the length of sentences and in the proportion of persons placed on probation are partly affected by variations in the size of the samples of cases involved in the comparisons; so that the results are, to some extent, a statistical artifact of comparing small numbers with large numbers. Nevertheless, a residue of considerable disparity remains; and the percentages and proportions still pose the question of the extent to which subjective influences enter into the process of individualization.

That the sentencing product in state courts is also very hard to explain or justify has been shown by several significant studies. Some time ago, for example, an analysis was made of over 7,000 sentences imposed by six judges over a nine-year period in a county in New Jersey. Each of these judges dealt with such crimes as larceny, robbery, burglary, embezzlement, assault and battery, rape, etc. Since there was no special assignment of cases to any particular judge, each judge received cases in which, considering them as a whole and over a long period of time, the felonies were committed under similar circumstances and the offenders, as groups, did not vary in general personal make-up and social background. Yet, the study disclosed that while Judge $A$ imposed sentences of imprisonment in thirty-six per cent of his cases and Judge $B$ in thirty-four per cent of his, Judges $C, D, E$, and $F$ imposed such sentences in fifty-three, fifty-eight, forty-five, and fifty per cent, respectively, of their cases. Thus, an offender convicted of a serious crime had but three chances out of ten of going to prison under Judges $A$ and $B$, and five chances out of ten if sentenced by Judges $C, D, E$, or $F$. Allowing the defendant to remain free in the community on probation, instead of sending him to prison, ranged, among the various judges, from twenty to thirty-two per cent; suspension of sentence, from sixteen to thirty-four per cent. Other American studies have shown similar discrepancies in courts of different states.

"1d. table 32, at 92.

'See Gaudet, The Sentencing Behavior of the Judge, in Encrclopedia of Criminology 449-61 (Branham and Kutash ed. r949). 
The writer once analyzed the sentences by judges in Massachusetts over a period of years, and he found a refinement in the exercise of judicial discretion that it would be difficult to justify. In I94 successive admissions to prison in one year, no fewer than fifty-three separate types of sentence were imposed. The sentences varied so much that there was great difficulty in reducing them to a few categories. A complex of motives is involved, including an attempt to influence the action of the parole board; but whatever the motives, how can one justify sentences that range from between $2 \frac{1}{2}$ years and three years at one extreme to between $42 \frac{1}{2}$ and forty-five years at the other? Even if the best available information regarding the characteristics and background of each offender was laid before the judges as a basis for the exercise of their discretion-and this is not uniformly the case-they could not possibly tell, in advance, that it would take $X$ from $2 \frac{1}{2}$ to three years to reform, $Y$ from $2 \frac{1}{2}$ to $3 \frac{1}{2}$ years, $A$ from forty to forty-five years, and $B$ from forty-two to forty-five years; or, if deterrence be stressed, that $X$ 's punishment should be half a year shorter or longer than Y's because they respectively need these different sentences to frighten them into not repeating their crimes, or the public requires this fine distinction to deter it from violating the various laws. Such ultraprecision is, on its face, irrational. It satisfies neither the prisoner's nor the public's conception of justice; nor does it meet the demands of a realistic individualization of sentence.

Sentencing erraticism is, of course, not limited to courts dealing with felonies; there is ample proof that it exists as well in the disposition of misdemeanants. Thus, as far back as rgr2, a Commission on the Inferior Courts of the County of Suffolk (Massachusetts) prepared a report showing wide differences in dispositions, by total and by individual offenses, in the various courts involved. The investigation concluded that ${ }^{5}$

these courts . . . exercise within their several districts the same criminal jurisdiction, ... . and although the social and economic conditions of their various districts do not differ essentially, there exists a radical and multiform variation and antagonism of practice in matters essential to the enforcement of law.

A study of the New York City magistrates' courts showed like variations in sentence. In the rgI4 report, the chief justice of those tribunals seems to have condoned this practice:

I have never attempted, although the power of assignment of magistrates to this court is vested in me, to lay down any iron-clad rules as to punishment, because individual cases exceptional in nature so often arise.

He overlooked the fact, however, that, given a large enough number of cases, the "individual cases exceptional in nature" would turn up about as frequently before one judge as another.

Bearing in mind the reflex effect of any process of justice on every other, it must, in fairness, be pointed out that not all the responsibility for the sentencing

'Comm'n on the Infertor Courts of the County of Suffolk, Mass., Report 7 (ig12).

- New York City Magistrates Court Ann. Rep. 20 (1915). 
situation is the judges'; prosecuting attorneys must take their share, for their recommendations as to sentence are involved. But, essentially, judges are the officials entrusted with the determination of sentence; and this decision has a significant effect on everything that follows: the place and length of possible or actual penocorrectional treatment. Commenting on the above-mentioned New Jersey study, the investigators fixed the judges' responsibility in the following reasonable manner: ${ }^{7}$

.. given a sufficient number of cases, one could expect that two judges would give sentences whose average severity would be about equal (providing that the judges were influenced only by the circumstances of the crime and those of the prisoner). Conversely, given a sufficiently large number of cases, if one finds that the average severity of the sentences of two judges is appreciably different, one is justified in saying that the factors which determine this difference in the sentencing tendencies are to be found outside the circumstances of the crime and those of the prisoner and hence probably in the judge, since he is the other factor which is always present.

The New Jersey study concluded that ${ }^{8}$

the sentencing tendency of the judge seems to be fairly well determined before he sits on the bench. In other words, what determines whether a judge will be severe or lenient is to be found in the environment to which the judge has been subjected previous to his becoming an administrator of sentences.

This is not a novel problem in the administration of justice. In England, at the turn of the century, Sir Henry Hawkins, an experienced magistrate, criticized sentencing practices in these words: ${ }^{9}$

The want of even an approach to uniformity in criminal sentences is no doubt a very serious matter, and is due, not to any defect in the criminal law (much as I think that might be improved in many respects), but ... to the great diversity of opinion, and therefore of action, which not unnaturally exists among criminal Judges. . . .

The result of this state of things is extremely unsatisfactory, and the most glaring irregularities, diversity and variety of sentences, are daily brought to our notice, the same offence committed under similar circumstances being visited by one Judge with a long term of penal servitude, by another with simple imprisonment, with nothing appreciable to account for the difference.

'Gaudet, Harris, and St. John, Individual Differences in the Sentencing Tendencies of Judges, 23 J. Crims. L. \& Crmmorogy 8ri, 813 (1933).

${ }^{B} I d$. at $8 \mathrm{r}_{4}$.

' 2 The Reminiscences of Sir Henry Hawkins Baron Brampton 285-87 (Harris ed. I904). See also S. Romilly, Observations on the Criminal Law in England as It Relates to Capital PunishMENTS, AND ON THE MODE IN WHICH IT Is ADMINISTERED 17 (1810), in which the author says:

"It has often happened, it necessarily must have happened, that the very same circumstance which is considered by one judge as matter of extenuation, is deemed by another a high aggravation of the crime. The former good character of the delinquent, his having come into a country in which he was a stranger to commit the offence, the frequency or the novelty of the crime, are all circumstances which have been upon some occasions considered by different judges in those opposite lights; and it is not merely the particular circumstances attending the crime, it is the crime itself, which different judges sometimes consider in quite different points of view." 
In one or the other of these sentences discretion must have been erroneously exercised. . . Experience, however, has told us that the profoundest lawyers are not always the best administrators of the criminal law.

Some legal philosophers have gone so far as to make a sort of virtue of erratic judicial practices. Thus, Ehrlich, discussing "freedom of decision" on the Continent, cheerfully regards the personality of the judge as the desirable crux of the problem. The administration of justice, he says, ${ }^{10}$

has always contained a personal element. In all ages, social, political and cultural movements have necessarily exerted an influence upon it; but whether any individual jurist yields more or less to such influences... depends of course less on any theory of legal method than on his own personal temperament. The point is that this fact should not be tolerated as something unavoidable, but should be gladly welcomed. For the one important desideratum is that his personality must be great enough to be properly entrusted with such functions. The principle of free decision is really not concerned with the substance of the law, but with the proper selection of judges; in other words, it is the problem of how to organize the judiciary so as to give plenty of scope to strong personalities. Everything depends upon that.

This is all very well. But how these "strong personalities," once they are brought into the judicial service, are to function efficiently without being erratic or prejudiced in their sentencing judgments is a basic issue that cannot be avoided. Discretion there should certainly be; but the problem is to provide a technique whereby discretion shall be allowed ample creative scope and yet be subjected to rational external discipline or self-discipline.

III

There are several ways of doing this. The familiar one is to permit sentence revision by some appellate body. ${ }^{11}$ But such a twice-removed tribunal could not greatly improve on the original sentencing practices, or at best could only bring about a superficial uniformity of sentence. ${ }^{12}$ The basic problem-the proper exercise of creative discretion at the sentencing and releasing stages-cannot be met in this way.

Another device is detailed legislative prescription of criteria to be applied by the judge in assessing the length and nature of the sentence. The difficulty here is that the legislature may surround the judge with so clumsy an apparatus of control as to permit of but a poor counterfeit of scientific individualization. An illustration of a legislative attempt to cabin and confine judicial discretion is the Italian penal

${ }^{20} \mathrm{E}$. Ehrlich, Judicial Freedom of Decision: Its Principles and Objects, translated from his Freie Rechtsfindung und Freie Rechtswissenschaft (I903), in ScIENCE of Legal. METHOD 47, 74 (E. Bruncken transl. 1921).

${ }^{11}$ See Sobeloff, The Sentence of the Court: Should There Be Appellate Review?, 4I A.B.A.J. I3 (1955).

${ }_{13}$ This is the distinct impression obtained by the author from an analysis of a large sample of the decisions of the English Court of Criminal Appeals. See, also, Hall, Reduction of Criminal Sentences on Appeal, 37 Colum. L. REv. 521, 762 (1937). 
code project of the late Professor Enrico Ferri. ${ }^{13}$ In accordance with his policy of emphasizing the dangerousness of the offender and, at the same time, providing for "necessary guarantees" of the individual's right to uniformity of consideration at the sentencing stage, Ferri furnished an elaborate schedule of "conditions of dangerousness" and "conditions of less dangerousness" to be prescribed by the penal code in advance and to be applied by the judge as a basis for computation of the type and length of the individual convict's penal treatment. At the same time, he emphasized the need of providing for "segregation for a period relatively or absolutely unlimited."

He listed no fewer than seventeen "circumstances which indicate a greater dangerousness in the offender," and eight circumstances of "less dangerousness." Among the former, he included such items as "dissoluteness or dishonesty of prior personal, family, or social life"; "precocity in committing a grave offense"; "having acted through ignoble or trivial motives"; "time, place, instruments, manner of extcution of the offense, when these have rendered more difficult the defence by the injured party or indicate a greater moral insensibility in the offender"; "execution of the offense by means of ambush or stratagem or through the commission of other offenses or by abusing the aid of minors, the deficient, the unsound of mind, the alcoholic"; and other such considerations. Among the circumstances presumed to indicate "less dangerousness in the offender," Ferri's code lists, for example, "honesty of prior personal, family, and social life"; "having acted from excusable motives or motives of public interest"; "having yielded to a special and transitory opportunity or to exceptional and excusable personal or family conditions"; "having in repentance confessed the offense" not yet discovered or before being interrogated by the judge; and other such considerations.

Doubtless these are all useful and relevant hints; and similar data are, of course, often taken into judicial account, whether prescribed in a statute or not. But the Ferri code contains numerous directives regarding the application of these criteria to measure off the dimensions of the judge's discretion. For example, it is provided that "if there occurs only one circumstance of greater dangerousness, the judge shall apply the sanction in a measure not less than half between the minimum and the maximum set forth for the offense committed by the accused"; and "if there occurs only one circumstance of less dangerousness, the judge shall apply the sanction in a measure less than half between the minimum and the maximum." Similarly, other fractions of the total indeterminate sentence are to be measured off, depending on the presence of two or more circumstances of dangerousness or of less dangerousness.

The Ferri code also provides an elaborate system of punishments ("sanctions") which must be taken into account by judges in connection with the conditions of dangerousness and of less dangerousness, thus further complicating the process of

1s For a more extended and detailed exposition and analysis of this work than is here indicated, see S. Glueck, Principles of a Rational Penal Code, $4 \mathrm{I}$ HARv. L. REv. 453 (1928), reprinted in S. Glueck, Crime and Correction 72 (1952). 
individualization. For example, for ordinary offenses by persons over eighteen, it provides the "mulct" (a species of fine); "local relegation" (prohibition of residence in the place of the offense for from three months to three years); "confinement" (compulsion to reside in the commune named in the sentence, which must be "distant not less than roo kilometres" from that where the offense occurred, where the injured party resides, and where the offender resides); obligatory day labor (in workhouse or agricultural colony, without night detention, for from one month to two years); simple segregation in workhouse or agricultural colony (with compulsory industrial or agricultural day labor and night isolation for from three months to fifteen years, the type of labor to conform to "the previous life and aptitudes for labor" of the convict); and rigorous segregation in "an establishment of seclusion" (with compulsory day labor and night isolation for from three to twenty years, or for an indeterminate period of not less than ten years). There are similarly elaborate provisions to be juggled by the judge in the case of social-political offenders, juvenile offenders, and adults in a state of "mental infirmity"; and there are "complementary sanctions" to be taken into account, such as special publication of the sentence, suspension from exercise of trade or profession, interdiction from public office, expulsion of a foreign convict, binding over for good behavior, etc.

The foregoing analysis provides a vivid conception of what can happen when the code drafter or legislature concocts a clumsy admixture of the oil of discretion and the water of rule. The Ferri system is so mechanical and complicated in conception and design that one has a picture of a judge checking up on whether, say, "circumstances of greater dangerousness" numbered $1,3,7$, ro, 12 , and I7 and "circumstances of less dangerousness" numbered 2, 4, 6, and 8 are applicable to a defendant before him; ascertaining which of the numerous sanctions or combinations thereof are pertinent; then, using a computing machine to figure out just how much incarceration is called for in the application of the individual's sentence and where. In making such detailed provisions to be automatically applied at the time of sentence by means of a judicial arithmetic, the purpose of realistic individualized treatment is largely defeated.

Is it not possible to have a less mechanical system which will still guide judges in the process of individualization?

This is attempted in the sentencing provisions of the Model Penal Code, which the American Law Institute is in process of drafting. ${ }^{14}$ Section 7.or, for example, provides "Criteria for Withholding Sentence of Imprisonment and for Placing Defendant on Probation":

(r) The Court may deal with a person who has been convicted of a crime without imposing sentence of imprisonment if, having regard to the nature and circumstances of the crime and to the history and character of the defendant, it deems that his imprisonment is unnecessary for protection of the public, on one or more of the following grounds:

14 Model Penal Code 47-52 (Tent. Draft. No. 4, 1955). The Chief Reporter is Professor Herbert Wechsler; the sentencing provisions are largely the product of Professor Paul W. Tappan, Associnte Reporter. 
(a) The defendant does not have a history of prior delinquency or criminal activity, or having such a history, has led a law abiding life for a substantial period of time before the commission of the present crime;

(b) The defendant's criminal conduct neither caused nor threatened serious harm;

(c) The defendant did not contemplate that his criminal conduct would cause or threaten serious harm;

(d) The defendant's criminal conduct was the result of circumstances unlikely to recur;

(e) The defendant acted under the stress of a strong provocation;

(f) The victim of the defendant's criminal conduct consented to its commission or was largely instrumental in its perpetration;

(g) The imprisonment of the defendant would entail excessive hardship because of his advanced age or physical condition;

(h) The character and attitudes of the defendant indicate that he is unlikely to commit another crime.

(2) When a person who has been convicted of a crime is not sentenced to imprisonment, the Court shall place him on probation if he is in need of supervision, guidance or direction that it is feasible for the probation service to provide.

The Model Penal Code provides other criteria to be taken into account in the imposition of fine and for sentence of imprisonment. For example, among the criteria for a sentence of "extended term" of imprisonment which the court may impose on a person convicted of a felony, section 7.03 specifies:

( $\mathrm{I}$ ) The defendant is a persistent offender whose commitment for an extended term is necessary for protection of the public. ...

(2) The defendant is a professional criminal whose commitment for an extended term is necessary for protection of the public. ...

(3) The defendant is a dangerous, mentally abnormal person whose commitment for an extended term is necessary for protection of the public. ...

(4) The defendant is a multiple offender whose criminality was so excessive that a sentence of imprisonment for an extended term is warranted....

True, many judges tend, at present, to take into account the type of criteria included in the Model Penal Code; but the spelling of them out should be helpful in reminding judges to consider, systematically, various matters deemed relevant by the code drafter. Unlike the situation in the Ferri code, freedom of judicial discretion remains unhampered; but the listing of the considerations to be taken into account should, in the long run, bring about greater sentencing consistency. Still, as will be indicated shortly, even such a device is inadequate.

An approach similar to that of the American Law Institute has recently been taken by a distinguished Advisory Council of Judges, of the National Probation and Parole Association, in Guides for Sentencing. After soundly advising the judge that "moderation and objectivity should be his goals,"15 this publication provides some useful hints as to the kind of factors the judge should take into account. Some of these are similar to and may have been suggested by the factors which have

${ }^{15}$ Advisory Council of Judges, NPPA, Guides for Sentencing 7 (I957). 
emerged in follow-up and predictive research as relevant to expectable subsequent behavior. This is true, for example, of the following: $:^{16}$

The defendant whose first involvement in crime came late in life is more likely to succeed on probation than one who began at an early age and has continued in criminal behavior since then.

Again, ${ }^{17}$

The defendant whose parents, brothers, and sisters have respected society's demands of law and order, whose family life demonstrates mutual love and consideration, whose parents have given him reasonable and consistent discipline, and whose family members are eager to help him, is a better probation risk than one who does not have these advantages.

As in the case of the Model Penal Code's criteria, such suggestions are helpful; but they are insufficient. For the judge has no way of knowing how closely related such suggested factors are to various types of postsentence behavior. The criteria have not been evaluated regarding the relative weight to be assigned to them in the total size-up of the offender. This can only be done through systematic follow-up investigations which have related numerous traits and factors in the make-up and background of various types of offenders to their actual postcorrectional conduct.

The question thus presented is whether there is available, for the purposes of scientific differentiation of treatment, an instrument that can aid the judge in determining which factors have been demonstrated, by systematic analysis of objectified past experience, to be truly relevant to the expectable behavior of various offenders, and how much relative weight to give such factors in the particular case before the judge for sentence.

\section{IV}

This brings one to a striking, yet usually overlooked, aspect of the history of penology and code drafting; namely, that all the reform devices of the present century-the juvenile court, probation, the indeterminate sentence, classification within institutions, parole-depend for their efficiency on the reasonable predictability of human behavior under given circumstances. Yet, all these forward-looking additions to the apparatus of criminal justice were adopted long before this indispensable basis for their success-predictability-was available, and they still ignore or minimize the crucial element of predictability.

Since scientific individualization of justice promises to reduce recidivism, it is desirable. But can it not be more efficiently brought about than by merely supplying the judge with a set of criteria which he should, more or less, take into account, without knowing their relative weights in terms of expectable behavior, and which

${ }^{10} \mathrm{Id}$. at $3^{8}$. This age factor has been proved to be of great significance in numerous follow-up studies. See note 20 infra.

${ }^{13}$ Ibid. This statement is reminiscent of the Glueck Social Prediction Table derived from S. Guurck and E. T. Glueck, Unraveling Juvenile Delinguency 260-62 (1950). But it should be noted that, unlike that table, it does not indicate the relative weight to be accorded good discipline as opposed to poor, family cohesiveness as opposed to family disintegration, parental affection as opposed to various types of parental neglect. 
many dedicated and intelligent judges nowadays actually do take into account anyhow?

Some American and a few foreign criminologists believe that the answer lies in the prognostic instrument known as the prediction table. In several follow-up researches which have checked on the posttreatment careers of various classes of ex-prisoners, Dr. Eleanor T. Glueck and the writer have constructed a series of prognostic instruments which they believe give reasonable promise of ultimately bringing about better sentencing practices and treatment results than are achieved at present. It would require too extensive a discussion to describe and illustrate in detail the predictive devices developed for sentencing to various types of imprisonment, for placement on probation, for release on parole, and for predicting the postparole conduct of former prisoners over a considerable span of time. Their various publications, moreover, render full account of the techniques of prediction. ${ }^{18}$ A brief exposition of the method, however, is justified by way of illustration.

In their first study, 500 Criminal Careers, they thoroughly investigated the preinstitutional life histories of 500 former inmates of the Massachusetts Reformatory for young-adult felons during a five-year postparole "test period" following their discharge from that institution. Some fifty factors in the constitution, social background, and behavior of these offenders, from childhood through the parole and postparole periods, were explored and analyzed. By means of correlation tables, the degree of relationship between each of these biologic and social factors and the postparole behavior of the men was determined. To give one example, in respect to their prereformatory industrial habits, the men were subclassified into "good worker," "fair worker," and "poor worker."10 By correlating each of these industrial categories with the criminal behavior of the men during the five-year test period, it was found that of the good workers, forty-three per cent continued to commit crimes during the postparole test period; among the fair workers, fifty-nine per cent recidivated; and of the poor workers, sixty-eight per cent were criminalistic.

${ }^{18} \mathrm{~S}$. and E. T. Glueck, 500 Criminal Careers (I930), One Thousand Juvenile Delinguents (1934), Five Hundred Delinquent Women (1934), Later Crimnal Careers (i937), Juvenile Deinguents Grown Up (r940), Criminal Careers in Retrospect (i943), After-Conduct of Discharged Offenders (1945), Unraveling Juvenile Delinguency (1950). See also, E. T. Glueck, Spotting Potential Delinquents: Can It Be Done?, Federal Probation, Sept. 1956, p. 7. For a scholarly survey of many prediction studies in the United States (not including, however, the prognostic devices developed in Unraveling Juvenile Delinquency), see Monaschesi, Prediction of Criminal Behavior, in EncyciopediA of Criminology 324 (Branham and Kutash ed. 1949), American Studies in the Prediction of Recidivism, 4r J. CriM. L. 269 (1950).

${ }^{20}$ Good worker: One who is reliable, steady, industrious, shows promise of continuing in regular employment, and is commended by his employers.

Fair worker: One who has the qualifications of the regular worker, but who permits his work to be interrupted by periodic drinking, the drug habit, occasional vagabondage, stealing, or the deliberate choice of irregular occupations, such as longshoring, for the chief purpose of having leisure time.

Poor worker: One who is unreliable, a loafer, lazy, dishonest, unstable, a vagabond, and wayward.

These factors were considered independently of the nature of the employment (except where support was derived through proceeds of prostitution or other illegitimate occupations) or seasonal or other fluctuations in industry, and they express the man's general disposition toward work. The judgments were based upon the combined opinions of employers, police, and relatives, the last being given the least weight. Thus, a poor worker is one who, in the long run, constitutes a liability to the employer. 
These percentages we call "failure-scores," because they indicate the proportion of the different subclasses of men who failed to reform, considered from the point of view of their status in respect to such a factor as prereformatory industrial habits.

Similar correlations were established between each of the fifty biologic and sociologic factors, on the one hand, and the actual postparole behavior, on the other, with the result that many factors were found to bear very little relation to recidivism, while some showed a very high association therewith. ${ }^{20}$ In addition to industrial habits preceding entrance to reformatory, the following five factors, among those of greatest relationship to postparole conduct, were then employed in the construction of a table which judges could use in the sentencing of offenders: (I) seriousness and frequency of prereformatory crime; (2) arrest for crimes preceding the offense for which sentence to the reformatory had been imposed; (3) penal experience preceding reformatory incarceration; (4) economic responsibility preceding sentence to the reformatory, and (5) mental abnormality. ${ }^{21}$

By adding all the lowest percentages of failure (recidivism) associated with the various subcategories of these six factors, on the one hand, and all the highest, on the other, the two possible limits of "total failure-scores" were determined. These turned out to be 244 as the lowest and 396 (or more) as the highest. Within this range of lowest and highest total failure-scores, the following subclasses of total failure-scores were then established: 244-295, 296-345, 346-395, and 396 and over. Finally, all 500 cases were distributed in a table according, on the one hand, to each offender's total failure-score on all six predictive factors and, on the other, to whether, so far as postparole behavior is concerned, he turned out to be a success, partial failure, or total failure. ${ }^{22}$

${ }^{20}$ Thus, the coefficients expressing the relationship between the failure-score on the factors used in the prognostic instrument were high, ranging from .44 to .68 , the greatest possible value of the Pearsonian "mean square contingency coefficient" in a threefold table being .82. But the coefficient expressing the relationship between the type of offense committed-that is, whether it was a burglary, larceny, robbery. or sexually-motivated crime-and postparole recidivism or reform was only .12; and the coefficient of contingency measuring the relationship of the seriousness of the offense for which the men were sentenced to the reformatory and their posteriminal record was only .05 , or practically nil. Yet, the disposition of cases is fundamentally based on these latter factors!

22 The percentages of "total failures" for the subeategories of the above factors are:

(I) serious offender, $67 \%$; frequent minor offender, $53 \%$; occasional minor offender, $35 \%$; nonoffender, $21 \%$;

(2) offenders with prior arrests, $69 \%$; those without prior arrests, $32 \%$;

(3). offenders with prior penal experience, $74 \%$; those without prior penal experience, $47 \%$;

(4) economically-responsible offenders, $41 \%$; economically-irresponsible offenders, $64 \%$; and

(5) offenders showing no marked mental abnormality at time of entrance to reformatory, $60 \%$; psychopatbic personalities, $75 \%$; psychotics, $87 \%$.

22 Success: No police or court record, except occasional technical automobile law violations; no dishonorable discharge or desertion from armed forces; and no actual commission of individual criminal acts, whether or not arrest or prosecution resulted.

Partial Feilure: Conviction on two minor offenses; or arrest for not more than three minor offenses, or five technical automobile or drunkenness offenses, not followed by conviction; or arrest for not more than two serious offenses not followed by conviction; or arrest for one serious offense not followed by conviction, and not over two minor offenses not followed by conviction or occasional minor offenses. for which the violator of the law was neither arrested nor prosecuted (i.e., cases of sporadic, rather than 
Total Score

on

Status Regarding Postparole Criminality (percentage)

\begin{tabular}{crcc} 
Six Factors & Success & Partial Failure & Total Failure \\
\hline $244-295$ & 75.0 & 20.0 & 5.0 \\
$296-345$ & 34.6 & 11.5 & 53.9 \\
$346-395$ & 26.2 & 19.1 & 54.7 \\
396 and over & 5.7 & 13.7 & 80.6 \\
\hline All cases & 20.0 & 15.6 & 64.4 \\
\hline
\end{tabular}

From such a table, a judge who is considering whether or not to sentence any particular offender to a reformatory can, with reasonable accuracy, determine the advisability of such disposition of the case before him, provided he has reliable information as to that offender's status in respect to the six simple predictive factors upon which this prognostic instrument is based. A prisoner scoring as low as 244 to 295 on these six factors-which have been found, by comparison of factors with outcomes in hundreds of cases, to be relevant to the question of reform or recidivism -belongs to a class that has about $7^{1 / 2}$ out of ten chances (75:100) of turning out a success-i.e., of not committing crimes during the postparole period. On the other hand, one with as high a failure-score as 396 or over has but half a chance out of ten (5.7:100) of succeeding under this type of penocorrectional treatment. The first man also has two out of ten chances (20:100) of failing only partially and only half a chance out of ten (5:100) of turning out a total failure. The second has only $\mathrm{I} 1 / 2$ chances out of ten (I3.7:I00) of partial failure and the high probability of eight out of ro chances (80.6:100) of turning out to be a complete failure.

Since this first table was published, Dr. E. T. Glueck and the writer have improved and refined many predictive instruments and have prepared them for each of the existing types of correction-e.g., probation with and without suspended sentence, jail, industrial school, reformatory, prison, and parole-for predicting varied response when offenders reach different ages, and for success or failure during a fifteen-year follow-up span. ${ }^{23}$ By consulting a battery of tables covering all available forms of penocorrectional treatment, a judge could bring to bear on the instant case the added light of systematized and objectified experience, gleaned from hundreds of prior cases, regarding the behavioral potentialities of the individual before him for sentence.

\section{$\mathrm{V}$}

But do such tables really work? Although many check-ups on various samples

continuous, misconduct definitely known to have occurred, but as to which no official action was, for various reasons, taken).

Total Failure: Arrest for three or more serious offenses not followed by conviction; or arrest for more than three minor offenses, except technical automobile or drunkenness offenses not followed by conviction; or convictions for one or more serious offenses; or convictions for more than five technical automobile or drunkenness offenses; or desertion or dishonorable discharge from the armed forces; or fight or escape from justice; or known commission of one or more serious offenses or a continuous course of minor offenses for which the violator of the law somehow was neither arrested nor prosecuted.

${ }^{28}$ Dr. E. T. Glueck and the writer have recently completed a book, which will be published in due course, under the title Predicting Delinquency and Crime. 
of cases are desirable, the probable effectiveness of such tables is today beyond mere speculation. Validation of the prognostic instruments by applying them to other large samples of offenders is most encouraging. For example, one of the tables Dr. E. T. Glueck and the writer presented in Criminal Careers in Retrospect in I943 deals with the conduct of the former prisoners of the Massachusetts Reformatory as soldiers in the armed forces during the First World War. By applying that table to a random sample of 200 soldiers who had committed crimes while in the Army in the Second World War, it was demonstrated that in 84.5 per cent of the 200 cases, the prediction table would have foretold that the young men in question would commit military offenses; while in an additional ten per cent of the cases, the table would have shown that the chances of the young men not committing offenses while in the Army were only fifty-fifty. ${ }^{24}$

But much more important is a recently completed validation experiment involving many cases and various types of sentence. Dr. Eleanor T. Glueck and the writer have recently completed a detailed check-up of the predictions based on their tables in Juvenile Delinquents Grown $U_{p}$ (1940), which had been systematically applied, case by case, as each boy was studied, to the $5^{00}$ delinquents in Unraveling Juvenile Delinquency (1950). After a sixteen-year intensive follow-up, convincing evidence has been obtained that the tables in question actually did predict the behavior of these 500 youths while on straight probation, on probation with suspended sentence, in industrial schools, in reformatories, in prisons, on parole, and during a substantial follow-up period thereafter, and they did so with a total of eighty-six per cent accuracy. The detailed results will be published in due course.

While other validations are desirable, there is sufficient promise in the method to justify its cautious experimental use at the sentencing and paroling stages; and, indeed, prediction devices have for some years been employed by the Illinois Parole Board. $^{25}$

While on the subject of whether prediction tables will work or not, it is relevant to refer to the capacity of these tables to forecast future delinquency or nondelinquency on the part of very young children not yet showing signs of delinquency. There has recently been published an Interim Report of the New York City Youth Board, An Experiment in the Validation of the Glueck Prediction Scale, Progress Report from November, 1952 to December, 1956 (1957). Since the follow-up of the cases included in that validation experiment is only half-way along in time (the boys ranged from $5 \frac{1 / 2}{2}$ to $61 / 2$ years of age when the Youth Board workers applied the prediction scores from Unraveling and are now around $9 \frac{1}{2}$ to $101 / 2$, while the average of the boys in Unraveling was $141 / 2$ ), one must be cautious in interpreting the results thus far obtained. But readers who consult that report and examine

"s Schneider, LaGrone, E. T. Glueck, and S. Glueck, Prediction of Behavior of Civilian Delinquents in the Armed Forces, 28 MENTAL Hygiene 456, 467 (1944). For a detailed analysis of validations of the Glueck Social Prediction Table for early discovery of potential delinquents and for a device for distinguishing juvenile delinquents from youthful neurotics, see E. T. Glueck, Identifying luvenile Delinquents and Neurotics, 40 Mental Hygiene 24 (1956).

${ }^{25}$ See Lioyd E. Ohtin, Selection for Parole (I95I). 
tables nine, ten, and eleven thereof, will see proof that, so far, there is an approximately ninety per cent success of the Glueck Social Prediction Table in distinguishing, at the stage of their entrance into first grade, between those boys who, in the absence of timely and effective intervention, will later become delinquent and those who will not. This, despite the fact that the original table was largely based on a sample of Irish, Italian, Polish, and English-American boys and contained but two per cent of Jewish boys, while in the New York experiment, it was applied to Negro, Puerto Rican, and both non-Jewish and Jewish white boys.

This validation, together with other validations of different samples of cases by a variety of investigators, ${ }^{26}$ makes it quite clear that the favorable results spring from the efficiency of the predictive instrument and cannot be attributed to the "long arm of coincidence." Thus, prediction tables, founded on the thorough and systematic interrelationship between relevant factors and subsequent behavior, give a promising answer to the question of individualization.

In recommending the use of prognostic devices, the aim is, of course, not to substitute statistical tables for judicial experience in the sentencing of offenders. It is rather to supply the judge with an instrument of high promise in his work of individualizing justice. A judge should not follow these tables blindly; indeed, proof of a mechanical use of the tables might even raise an issue of denial of due process. The tables are, rather, designed to help the judge to see the individual offender in the perspective of organized experience with hundreds of other offenders who, in many crucial respects, resemble the person before him for sentence. The dimensions of the special problem each offender presents can be much more accurately assessed by the judge if he compares the crucial prognostic traits in the individual case with the total picture of hundreds of other offenders than if he relies exclusively on his unorganized experience or on a check-through of statutory criteria which, although listed, must still be weighed and assessed in each case and which have not been evaluated in regard to their relevancy in terms of their relationship to recidivism or reform..$^{27}$

But the use of prediction tables should not be lightly embarked upon. During the immediate future, it is preferable for a judge to continue to make his sentencing decision in each case as he does at present; then, to consult prediction tables and set down the predictive indications. After a few years, a thorough follow-up investigation can be made to compare outcomes on the basis of the existing ad hoc method with outcomes as predicted by the tables.

${ }^{20}$ See, e.g., E. T. Glueck, Spotting Potential Delinquents: Can It Be Done?, Federal Probation, Sept. x956, p. 7; Thompson, Further Validation of the Gluedk Social Prediction Table for Identifying Potential Delinquents, 48 J. CriM. L., C. \& P. S. 175-84 (I957).

${ }^{27}$ The argument that since the judge "saw the prisoner in court" and sometimes heard him testify, he is enabled to assess him expertly is obviously erroneous. In the first place, the crime and the brief contact with the prisoner in court are not only insufficient for a sound size-up, but may even be deceptive; in the second place, a considerable proportion of accused persons plead guilty and the judge can get very little idea about them. For these reasons, the probation officer's presentence report has assumed great importance. 
The prediction table, like the probation officer's presentence report, is but one instrument in aid of the individualizer of justice. A basic integration of the judge's sentencing role with the work of classification, treatment, and parole should improve the entire picture. If a clinical reception and classification center were established in the federal system for each circuit or in the state system for some appropriate administrative and jurisdictional area, if convicted persons were sent to such a regional center for a few weeks' observation and study, and if the judges were then furnished a comprehensive report on each offender, in which the relevant predictive factors were included, they would be in a better position than they are today to tailor the sentence to the individual case. ${ }^{28}$

Indeed, even greater integration seems desirable. The writer would favor a procedure which would permit of judges taking turns, on assignment by the chicf judge, in serving as chairman of a regional classification and parole board for a year's period. Under such a scheme, the sentencing judge would fix the minimum sentence to take account of community reaction and the claims of general deterrence; and the judicial arm-not necessarily the particular judge involved in the casewould participate in determining the place of incarceration, the corrective-therapeutic treatment program, and the time and conditions of parole. The suggested arrangement would have several values: it would, first and foremost, have a tendency to correlate sentencing practices with treatment and releasing policies; it would also give the legally-trained judge a realistic education in the relevancy of the behavioral disciplines to the carrying out of the mandates of justice; and, finally, it would furnish the necessary trained legal discipline and concern with a climate of due process at the treating, releasing, and supervisory stages. In brief, it would give both practical and symbolic reality to the policy that in the administration of justice, the nonlegal expert-psychiatric, psychologic, sociologic, educational, religious, or other-should be "on tap and not on top."

In this way, the judge can be aided in assuming the noble role of social physician that Aristotle, over two thousand years ago, had in mind when he said: ${ }^{20}$

... the knowing what is Just and what Unjust, men think no great instance of wisdom, because it is not hard to understand those things of which the laws speak. They forget that these are not Just actions except accidentally: to be Just they must be done and distributed in a certain manner: and this is a more difficult task than knowing what things are wholesome; for in this branch of knowledge it is an easy matter to know honey, wine, hellebore, cautery, or the use of the knife; but the knowing how one should administer these with a view to health, and to whom and at what time, amounts in fact to being a physician.

${ }^{28}$ Under the provisions of the Federal Youth Corrections Act, the youth offender may be sent by the district court to the classification center at Ashland, Kentucky, for a period of observation and study prior to sentence, and a report of the findings is submitted to the sentencing court.

${ }^{28}$ The Nicomachean Ethics book V, IX, Ir37a (Chase transl. 1934). 